\title{
COMPARATIVE STUDY OF RETENTION AND PERI-IMPLANT OUTCOME OF FOUR IMPLANTS USED TO RETAIN MANDIBULAR SINGLE OVERDENTURE PLACED IN LINEAR VERSUS QUADRILATERAL DISTRIBUTION
}

\author{
Salah AF Hegazy*
}

\begin{abstract}
Purpose: To compare the effect of linear versus quadrilateral distribution of four implants retained mandibular single overdenture using ball attachments on the retention of mandibular overdenture and on peri-implant outcome.

Materials and Methods: Twelve patients were selected for this study with average age from 40-60 .They had maxillary dentulous arches opposing mandibular edentulous arches. Maxillary occlusal plane rehabilitation was made .Mandibular single denture was constructed and duplicated in clear acrylic resin to be used as surgical stent. According to the distribution of implants, the patients were randomly divided into two groups; Group I where the four implants were distributed in a linear form in the interforaminal distance, two in the site of mandibular lateral incisor, and two in the mandibular canine site, group II where the implants were distributed in quadrilateral distribution in the canine, second premolar region. After osseointegration period, ball attachments were used to retain the mandibular single overdenture. The retention of the mandibular overdenture and the peri-implant outcome were evaluated using the following variables: (1) modified plaque index; (2) modified bleeding index; (3) probing depth; (4) implant mobility using the Periotest instrument. The measurements were evaluated at time of mandibular single overdenture insertion (T0), six month (T1), and twelve month (T2) after mandibular overdenture insertion.
\end{abstract}

Results: The descriptive statistics of retention showed statistically insignificant difference in the retention measurements at the three periods of time within the same group $(\mathrm{p}=0.493$ in group I and $\mathrm{p}=0.255$ in group II). However, there was statistically significant difference between the two studied groups at each observation time ( $<<0.001$ at the three observation times). The comparison of periimplant outcome showed statistically insignificant difference between two groups and statistically significant difference within each group, except implant mobility as it was zero mobility in both groups and along all the period of the study.

Conclusion: Quadrilateral distribution of four implants used to retain mandibular single denture is more advantageous than linear distribution, however further radiographic evaluation, and study the effect of using different attachments are recommended.

KEYWORDS: Single overdenture, linear, quadrilateral, and implants.

* Associate Professor of Prosthodontics, Faculty of Dentistry, Mansoura University. 


\section{INTRODUCTION}

It is common to find a patient who has become entirely edentulous in one jaw while retaining either all or some of his natural teeth in the other jaw. Usually this finding faces the dentist with challenges. This is related to firmness and rigidity with which the natural teeth are retained in the bone and the magnitude of the force they can resist or deliver without discomfort or displacement. This force has been recorded as high as $198 \mathrm{lb}$ on single molar teeth. This is in sharp contrast with the force which a complete denture, resting simply on the delicate mucosa of the ridge, can resist or deliver. This force has been established as being a maximum static load of $26 \mathrm{lb}^{(\mathbf{1})}$. The second reason is related to the discrepancy of occlusal form of the remaining natural teeth, which will of necessity dictate the occlusal form of the denture.

Single mandibular complete dentures suffer greater pressures as the basal seat area available is limited and the opposing arch consists more or less of natural teeth. ${ }^{(2)}$

The edentulous mandible presents a unique set of problems that must be compensated for if a mandibular prosthesis, opposing maxillary arch with all or part of natural dentition, is to be comfortable, functional, stable and non destructive. The remaining natural teeth can still generate substantial forces directed toward the mandibular residual ridge. Mandibular implant overdentures can often be used to advantage against remaining maxillary dentition ${ }^{(3)}$

Many studies have been conducted on the number of implants to be used in implant supported prostheses .In treatment planning, the number of implants to support the prostheses preferred was two or four and increasing the number of implants shifted the support from mucosal surface to implants ${ }^{(4)}$

The traditional implant-supported overdenture has a minimum of two implants inserted in the region of the mandibular canines ${ }^{(5)}$. This type of treatment helps reducing the resorption rate of the anterior ridge and increasing denture retention and stability, so that patients with overdentures report greater satisfaction than with conventional complete dentures ${ }^{(6-10)}$. Another point in favor of overdentures is the increased proprioception during speech and mastication with greater movement of the tongue and facial muscles and improved patient confidence (11). In comparison with an implantsupported fixed prosthesis, the overdenture also has the advantage of allowing easier cleaning as they are removable and supported by fewer number of implants ${ }^{(12)}$.

The effect of number and position of implants on the stress behavior of mandibular implant retained overdenture was investigated in invitro studies ${ }^{(13)}$

As ridge resorption occurs, the mandibular anatomy may affect available implant locations, ${ }^{(14-16)}$ which, in turn, may affect surgical planning and treatment outcomes. ${ }^{(17-18)}$ Furthermore, abutment and retention location affect the treatment outcomes and biomechanical effects of prosthesis design. (19-20) Missing from these discussions, however, is an analysis of the effect of implant location on these prosthetic and surgical factors.

So, the aim of this study was to compare different implant distribution either in linear or quadrilateral distribution regarding single mandibular overdenture retention and periimplant outcome. The null hypothesis is that there would be insignificant difference between the two groups.

\section{MATERIALS AND METHODS}

Twelve patients of age 40-60 with mean age 50 years were elected from the outpatient clinic, Prosthodontic Department, Faculty of Dentistry, Mansoura University, Mansoura, Egypt. All patients had dentulous maxillary arch opposing mandibular single edentulous arches. The inclusion criteria for patient enrollment were sanitary mucosa; 
mandibular edentulism for at least 6 month , type II or III interforaminal edentulous ridge in according to the classification proposed by Lekholm and Zarb ${ }^{(21)}$, The patients had good general condition; and class III to $\mathrm{V}$ resorption of the mandible according to Cawood and Howell, ${ }^{(22)}$ have a minimum bone height of $13 \mathrm{~mm}$ in the interforaminal area.

The exclusion criteria included the following: Poor supported maxillary teeth that indicated for extraction. Systemic diseases contraindicating implant surgery in the mandibular arch as diabetes or osteoporosis, metabolic bone disease, and previous tumors or irradiation at the head and neck region, parafunctional habits as bruxism, or smoking habits. The study protocol and objectives were explained to all participants before obtaining signed informed consent.

\section{Surgical and Prosthetic Procedures}

Maxillary and mandibular preliminary irreversible hydrocolloid impressions ${ }^{*}$ were recorded and poured in stone ${ }^{* *}$. After construction of autopolymerized acrylic resin (Acrostone, cold cure denture base material, Egypt) record bases and wax occlusal rims, tentative vertical and horizontal maxillomandibular relations were recorded. The casts were arbitrary mounted on mean value articulator to estimate the needed occlusal modifications.

For all patients, maxillary occlusal plane rehabilitation was performed in form of thorough periodontal therapy, enameloplasty, crown restoration when needed either alone or combined with root canal therapy for maxillary occlusal plane rehabilitation. The maxillary occlusal plane was adjusted to a readymade metallic template adjusted to a harmonious occlusal plane and mandibular conventional complete dentures were constructed according to the lingualized concept of occlusion. Fig.(1)

A clear acrylic resin duplicate was constructed of the present mandibular denture with metal radioopaque indication at anticipated implant location and used as a radiographic template that was then transformed to a surgical template by connecting metal tubes (of 4.5-mm diameter) at suggested implant sites. All surgeries were accomplished with the administration of local anesthesia and an antibiotic (2 $\mathrm{g}$ of amoxicillin1 hour before surgery). A crestal incision in the mandible was made amidst

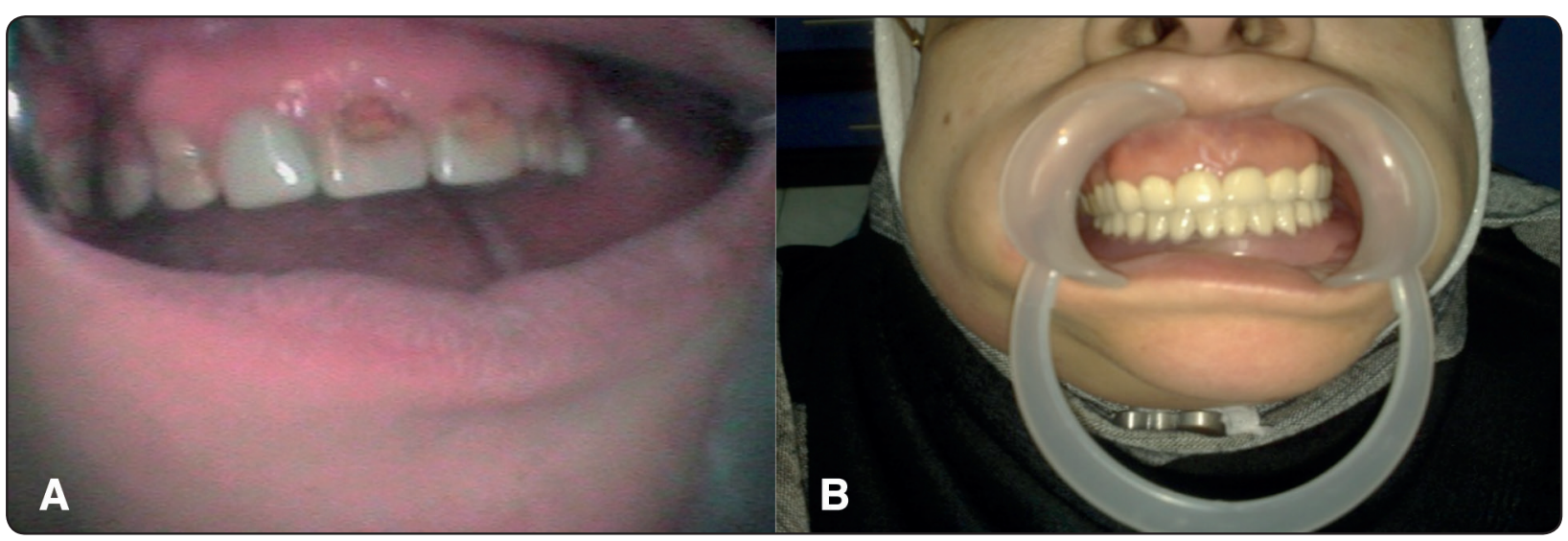

Fig. (1) A preoperative view, (B) rehabilitated maxillary arch opposing mandibular single denture

\footnotetext{
*Alginate Cavex, Holland,

**Elite stone, extra hard, zhermack, Italy
} 
the mental foramina. The mucoperiosteum was elevated and the bone softly drilled to prepare osteotomy positions for the implants. Each patient received four implants fixtures of $11.5 \mathrm{~mm}$ length and $3.6 \mathrm{~mm}$. diameter (Dyna helix, Dyna company, Holland), for Group I the four implants were distributed in a linear form in the interforaminal distance, two in the site of mandibular lateral incisor, and two in the mandibular canine site, and for group II the implants were distributed in quadrilateral distribution in the canine, second premolar region. The patients were prescribed a soft diet and informed to wash with $0.12 \%$ chlorhexidine mouthwash three times per day for 14 days. The patient had restricted follow up twice at first month and once in the second, third month. After osseointegration period of three month, Cover screws were unscrewed and healing abutments were linked to the implants for seven days. Healing abutments were removed and ball attachments with three $\mathrm{mm}$. collar height were linked to the implant fixture. Fig. $(2,3)$

Two stage full arch mandibular impression technique (selective pressure impression technique) was made according to the following procedures; In the first step: a zinc oxide euginol secondary impression for the ridge was made in a similar manner to that of a complete denture impression. - In the second step, anatomical impression of

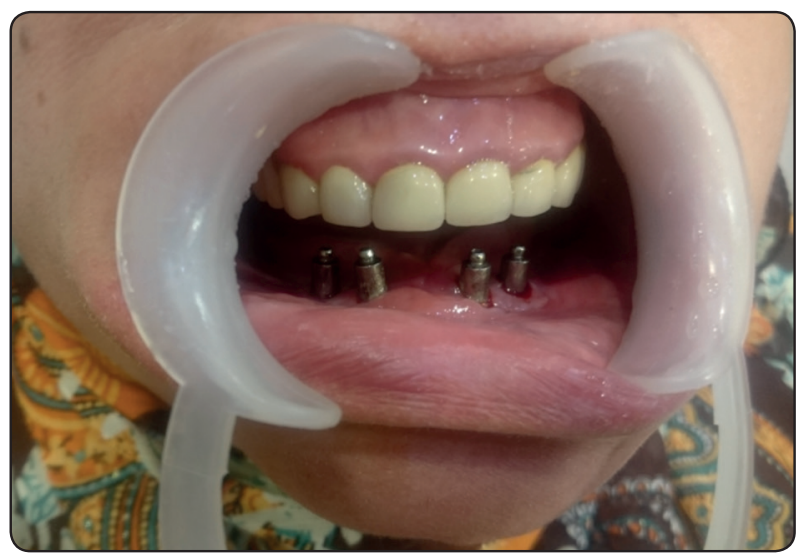

Fig. (2) Ball attachments for Group I with linear distribution the ball attachments was made. The custom tray was inspected intraorally to ensure that the ball attachments do not interfere with the tray insertion and removal. The tray was inserted in the patient's mouth and light body rubber base impression material was injected around the ball attachments from a plastic syringe (zhermack, heavy and light body condensation silicone impression material, Italy).

The mandibular secondary impression was poured in extra hard stone to obtain the mandibular master cast. Record blocks were constructed and the maxillary and mandibular casts were mounted on semi-adjustable articulator using maxillary arbitary facebow (ear bow) for maxillary casts mounting and centric inter-occlusal record for mandibular cast mounting.

Acrylic resin teeth of lingualized occlusal concept were arranged and tried in patient mouth according to esthetic and phonetics demands of the patient to achieve a lingualized balanced occlusion. The waxed dentures were tried -in with the keepers fixed in their position. The mandibular overdenture was processed from hard acrylic resin. The denture was laboratory remounted to correct processing errors and clinical remounting using a wax wafer to compensate for the effect of resiliency of the mucosa on occlusion.

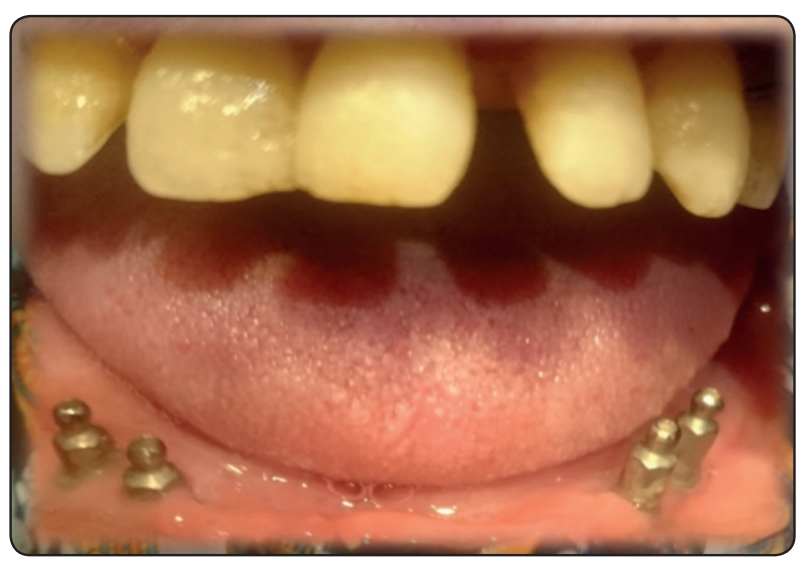

Fig. (3) Ball attachment for group II with quadrilateral distribution. 
The top surface of ball attachments were marked with indelible pencil to mark the intaligo surface of the mandibular overdenture. Fig. $(4,5)$

The marked areas were relived, and autopolymerizing cure resin was filled into the space left for ball attachments in intaglio surface of mandibular overdenture, placed in oral cavity and asked the patient to occlude till curing of resin. Excess of resin removed and occlusion was checked to remove interceptive occlusal contacts and finished denture was delivered to the patient. A venting hole was drilled lingually opposite to each ball attachment. The ball attachment was covered by plastic dummy on the functional pickup process. Fig.(6)

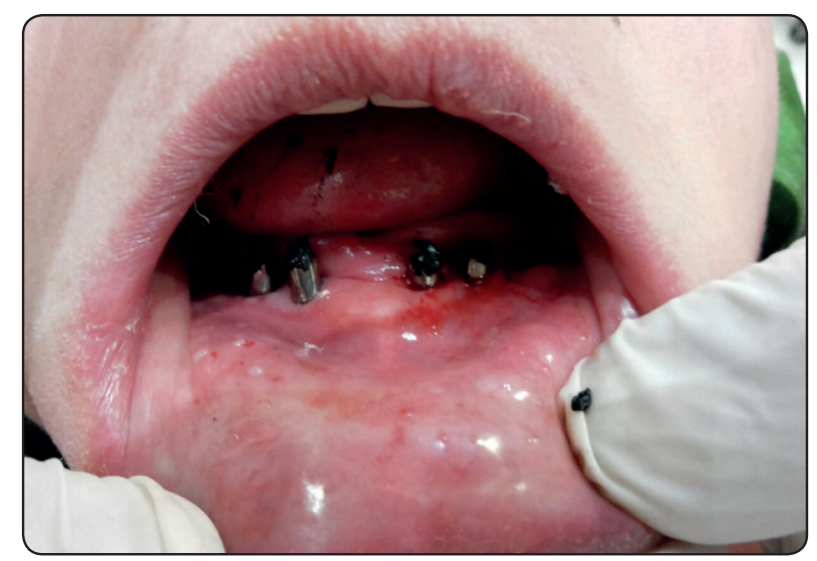

Fig. (4) Indelible pencil used to mark the top surface of ball attachment

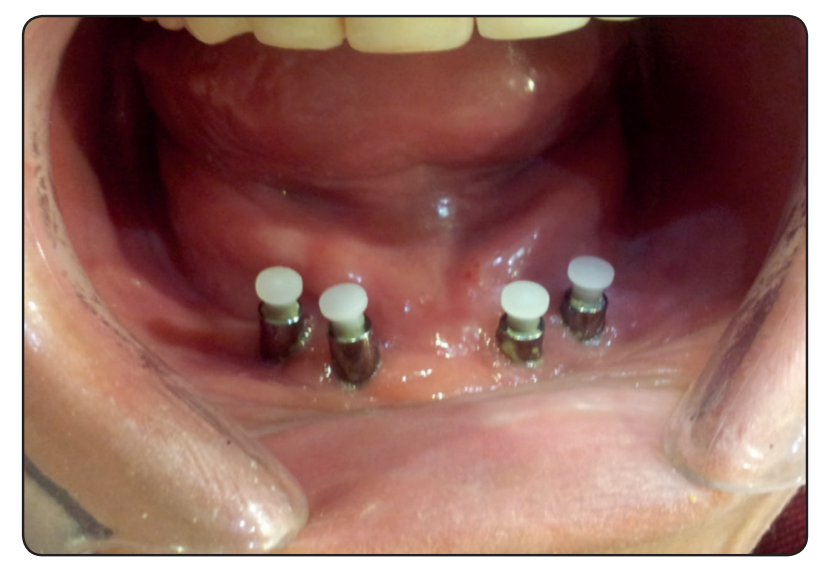

Fig. (6) Ball attachments covered by plastic caps during functional pickup process.
Excess acrylic material was removed and the mandibular overdenture was inserted and checked for proper occlusion and retention .Slight relief was made in the housing of ball attachment to allow a space of one $\mathrm{mm}$. of surface sealed soft liner (Promedica Company, Germany) that act as retentive element of the ball attachment. Fig.(7)

\section{Evaluation of retention:}

Retention of the mandibular overdenture were measured in the same patient immediately after mandibular overdenture, six and twelve months after mandibular ovredenture insertion

The retention of the mandibular complete overdenture was measured by using a digital forcemeter device according to David R Burns et al 2011; ${ }^{(23)}$ as following:

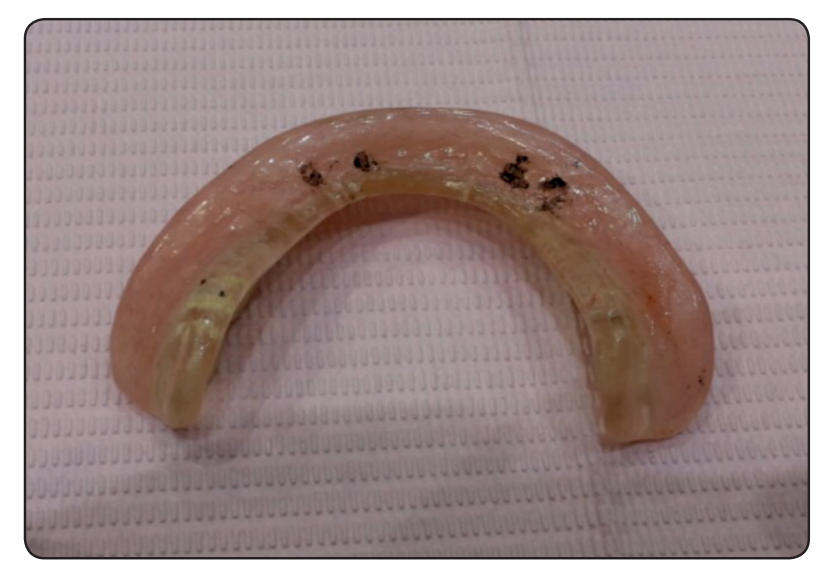

Fig. (5) The marked areas in the intaglio surface of the mandibular overdentures.

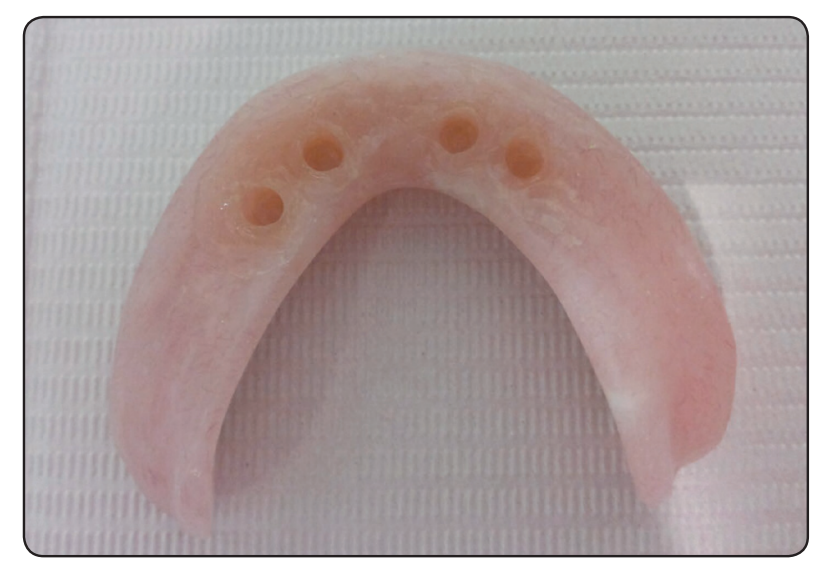

Fig. (7) The intaglio surface of the mandibular overdenture with the soft liner. 
The patient was seated in the dental chair in an upright position with the head resting firmly against the head rest. The mandibular overdenture was positioned correctly on the tissues and the patient was asked to rest the tongue passively in the floor of the mouth with the tip adjacent to the adjacent anterior denture teeth

Brass wire was secured to the mandibular denture. It was placed buccal to and below the first molars with cold-curing acrylic resin so the force meter device could exert a vertical dislodging force on the denture, and thus test its retention.

The hook attachment was placed on the shaft of the force meter device and the hook engaged the center of the brass wire loop. The pull end of the forcemeter device was connected to a $0.9 \mathrm{~mm}$ orthodontic wire that attached to a distal hook. The forcemeter device was pulled vertically until the denture was elevated. The force was measured in Newton and recorded as the denture's retention. For each patient, more than three records were taken each time and an average was taken. The measurements of retention were performed immediately after insertion (T0), after six month (T1), and after twelve months from mandibular overdenture insertion(T2) Fig.(8)

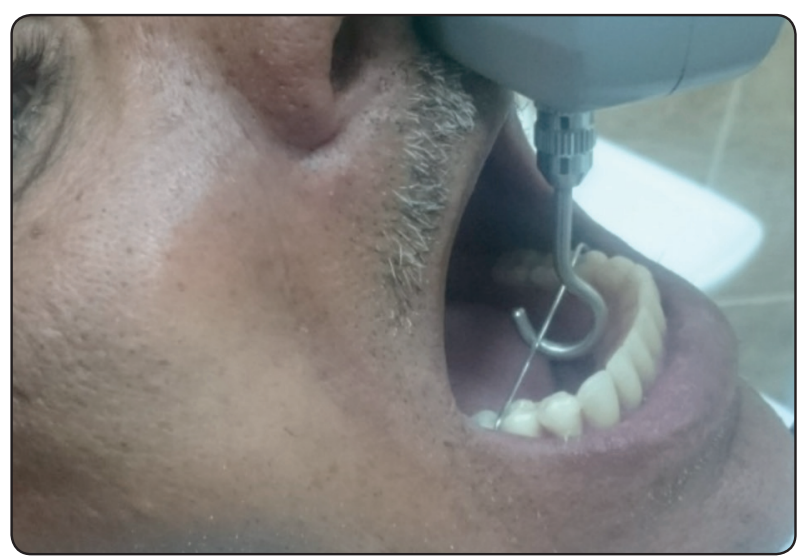

Fig. (8) Evaluation of retention by forcemeter guage

\section{Evaluation of periimplant outcome:}

The following implant-related outcomes were recorded at the overdenture insertion time (baseline, T0), and six months (T6) and twelve months (T12) after overdenture insertion.

1. Modified plaque index (MPI): The existence of plaque was estimated by the MPI, ${ }^{(24)}$ and ranked from 0 to 3 as follows: $0=$ no plaque find out, 1 $=$ plaque only observed by running a probe over the surface supragingivally, $2=$ plaque is visible unaided,= abundance of soft issue.

2. Modified bleeding index (MBI): Bleeding on probing was specified according to the modification of Mombelli and Lang from the original technique of Loe and Silness ${ }^{(25)}$ and ranked from 0 to 3 as follows: $0=$ no bleeding, $1=$ pinpoint bleeding, $2=$ linear bleeding, $3=$ profuse bleeding.

3. Probing depth (PD): For measuring peri-implant PD, span between the border of gingival margin and tip of the graduated periodontal probe (Vivacare TPS Probe, Ivoclar Vivadent) was assessed to the nearest $0.5 \mathrm{~mm}$. The propping depth was measured in buccal, lingual, mesial, and distal aspects of each implant and the mean was calculated for every implant and for the four implants in every patient of the groups. Fig.(9)

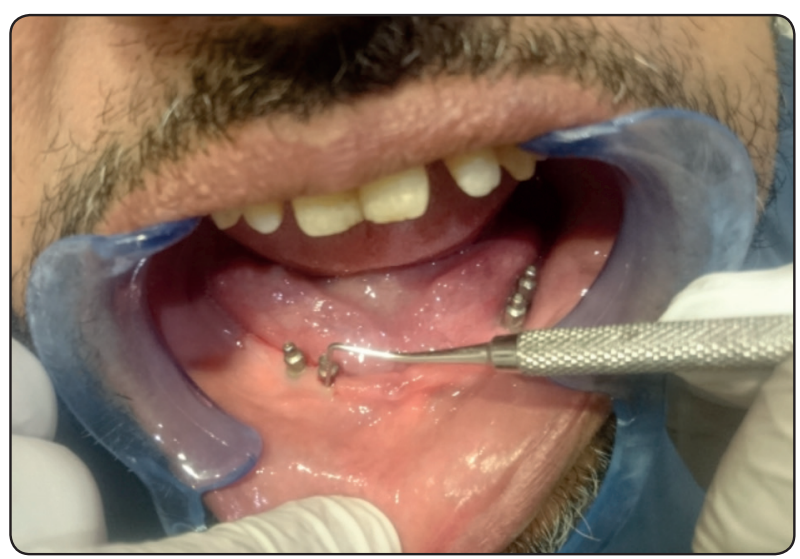

Fig. (9) Evaluation of probing depth 
4. Implant mobility: The Periotest instrument (Siemens) was used to evaluate implant mobility at the time of the implant placement and in subsequent visits using the Periotest value (PTV). ${ }^{(26-27)}$ The measurements were made at the abutment level with the rod held perpendicular to the longitudinal axis of the implants. Measurements were taken until two duplicate values were registered. The PTV scale extends from -8 to +50 . The lower the value, the greater the stability/damping effect of the measured implant. Fig.(10)

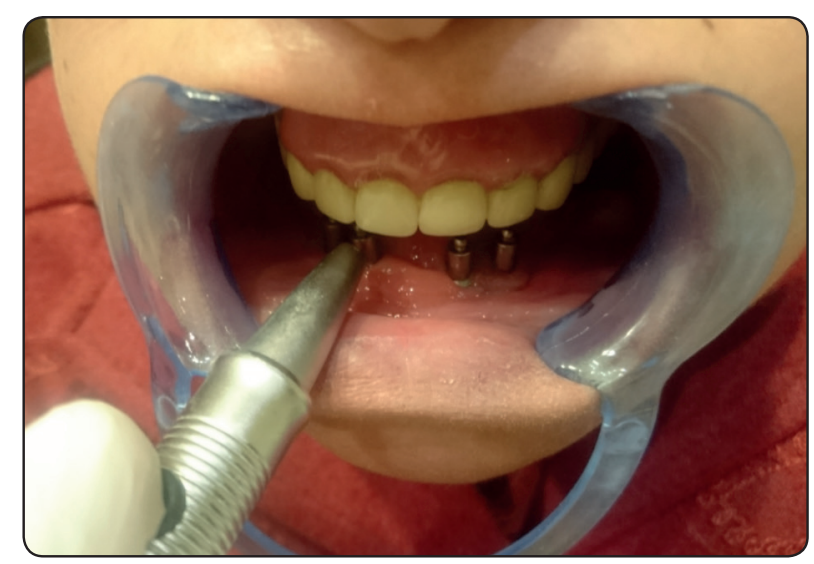

Fig. (10) Evaluation of implant mobility using periotest

\section{Statistical Analysis}

Statistical analysis of data was conducted by using the SPSS (statistical package for social science) program (SPSS, Inc, Chicago, IL) version 17. The Shapiro-Wilk test was used to determine the normal distribution of data. Nonparametric data (MPI, MBL, and PD) were presented using median values (minimum to maximum), whereas parametric data (retention) were demonstrated as mean \pm standard deviation. For nonparametric data, the Mann-Whitney test was used to compare the groups, Friedman test was used to compare data at the various observation periods within the group, and
Wilcoxon signed rank test was utilized to compare two observation periods within the same group. For parametric data, we utilized the independent $t$ test for comparison between both groups. $\mathrm{P}$ was look to be significant at .05 or less, using $95 \%$ confidence intervals.

\section{RESULTS}

Descriptive statistics of MPI, MBL, and PD for group I (linear implant distribution) and group II (quadrilateral implant distribution) at different observation times were presented in Table (1). MPI and PD increased significantly in both groups over time (Freidman test, $\mathrm{P}<.05$ ) while, MBI decreased significantly in both groups over time (Freidman test, $\mathrm{P}=0.006$ in both groups) as shown in Table (1).

At the three observation times (T0, T1 and T2), the changes in MPI, MBL, and PD between both groups was insignificant (Mann-Whitney Test, $\mathrm{P}>$.05) as shown in table (1). Multiple comparisons (Wilcoxon signed rank test) of MPI, MBL, and PD between each two observation periods for each group were represented in table (2).

Table (3) showed the descriptive statistics of retention of the two studied groups at the three observation times (T0, T1 and T2). Table (4) represented the retention measurements in the two studied groups at three different periods of time and revealed that, no statistically significant difference in the retention measurements at the three periods of time within the same group ( $\mathrm{p}=$ 0.493 in group I and $p=0.255$ in group II). As regard retention measurement, table (5) showed statistically significant difference between the two studied groups at each observation time $(\mathrm{p}<0.001$ at the three observation times). All measured data of periotest of all implants ranged from -5 to 4 which means zero mobility all over the period of study for both groups. 
TABLE (1) Comparison of plaque scores (MPI), Bleeding scores (MBI), and probing depths (PD) between the two groups at three different observation times.

\begin{tabular}{|c|c|c|c|c|}
\hline & T0 & T1 & $\mathbf{T 2}$ & $\begin{array}{c}\text { Freidman test } \\
\quad(p \text { value })\end{array}$ \\
\hline \multicolumn{5}{|c|}{ Plaque Scores (MPI) } \\
\hline Group I & $0.0(0.00-0.00)$ & $1.0(1-2)$ & $2.0(1-3)$ & 0.004 \\
\hline Group II & $0.0(0.00-0.00)$ & $1.0(0.0-2.0)$ & $1.5(1.0-2.0)$ & 0.008 \\
\hline Mann-Whitney Test (p value) & 1.00 & 0.484 & 0.423 & \\
\hline \multicolumn{5}{|c|}{ Bleeding scores (MBI) } \\
\hline Group I & $2.0(1.0-3.0)$ & $0.0(0.0-1.0)$ & $0.0(.0-0.0)$ & 0.006 \\
\hline Group II & $2.0(1.0-3.0)$ & $0.0(0.0-1.0)$ & $0.0(.0-0.0)$ & 0.006 \\
\hline Mann-Whitney Test (p value) & 1.0 & 1.0 & 1.0 & \\
\hline \multicolumn{5}{|c|}{ Probing depth (PD) } \\
\hline Group I & $1.0(0.5-1.5)$ & $1.5(1.0-3.0)$ & $2.5(1.5-3.0)$ & 0.004 \\
\hline Group II & $1.0(0.5-1.5)$ & $1.5(1.5-3.00)$ & $1.5(1.5-3.00)$ & 0.003 \\
\hline Mann-Whitney Test (p value) & 1.0 & 0.39 & 0.194 & \\
\hline
\end{tabular}

\section{Group1= Linear implant distribution}

$M=$ median, $\min =$ minimum $;$ max = maximum

\section{Group2= Quadrilateral implant distribution}

T0: immediately after placement of the attachment T1: six month after the placement of the attachment

T2: twelve month after the placement of the attachment

TABLE (2) Multiple comparisons of plaque scores (MPI), Bleeding scores (MBI), and probing depths (PD) between each 2 observation times for both groups (number in each cell indicate $\mathrm{p}$ value of Wilcoxon sign ranks test) :

\begin{tabular}{|c|c|c|c|}
\hline & T0-T1 & T0- T2 & T1-T2 \\
\hline \multicolumn{4}{|c|}{ Plaque Scores (MPI) } \\
\hline Group I & 0.023 & 0.026 & 0.083 \\
\hline Group II & 0.063 & 0.024 & 0.083 \\
\hline \multicolumn{4}{|c|}{ Bleeding scores (MBI) } \\
\hline Group I & 0.041 & 0.026 & 0.317 \\
\hline Group II & 0.041 & 0.026 & 0.317 \\
\hline \multicolumn{4}{|c|}{ Probing depth (PD) } \\
\hline Group I & 0.024 & 0.024 & 0.059 \\
\hline Group II & 0.026 & 0.026 & 0.317 \\
\hline
\end{tabular}

Group1= Linear implant distribution

$M=$ median, min= minimum; max= maximum

T0: immediately after placement of the attachment

T2: twelve month after the placement of the attachment
Group2= Quadrilateral implant distribution

$*=$ significant at $\leq 0.05$ level

T1: six month after the placement of the attachment 
TABLE (3) Descriptive statistics of retention of both implant linear and quadrilateral distribution groups at three different periods of time:

\begin{tabular}{|c|c|c|c|c|c|c|}
\hline & T0 & T1 & T3 & T0 & T1 & T2 \\
\hline & \multicolumn{3}{|c|}{ Group I } & \multicolumn{3}{|c|}{ Group II } \\
\hline Mean & 2.92 & 2.95 & 3.05 & 4.12 & 4.13 & 4.25 \\
\hline Median & 2.95 & 3.00 & 3.0 & 4.15 & 4.10 & 4.25 \\
\hline SD & 0.20 & 0.14 & 0.197 & 0.15 & 0.14 & 0.15 \\
\hline Minimum & 2.6 & 2.7 & 2.8 & 3.9 & 4.0 & 4 \\
\hline Maximum & 3.2 & 3.1 & 3.4 & 4.3 & 4.3 & 4.4 \\
\hline
\end{tabular}

Statistically significant $p<0.05$

T1: six month after the placement of the attachment
T0: immediately after placement of the attachment

T2: twelve month after the placement of the attachmen

TABLE (4) Retention measurements in the two studied groups at three different periods of time using oneway ANOVA test:

\begin{tabular}{|c|c|c|c|c|}
\hline $\begin{array}{c}\text { Type of implant } \\
\text { distribution }\end{array}$ & T0 & T1 & T2 & P \\
\hline Linear & $2.92 \pm 0.20$ & $2.95 \pm 0.14$ & $3.05 \pm 0.197$ & 0.493 \\
Quadrilateral & $4.12 \pm 0.15$ & $4.13 \pm 0.14$ & $4.25 \pm 0.15$ & 0.255 \\
\hline
\end{tabular}

Statistically significant $p<0.05$

T1: six month after the placement of the attachment
T0: immediately after placement of the attachment

T2: twelve month after the placement of the attachmen

TABLE (5) Comparison between the two types of implant distribution (studied groups) at three different periods of time:

\begin{tabular}{|l|c|c|c|}
\hline $\begin{array}{c}\text { Type of } \\
\text { Implant disrtibution }\end{array}$ & T0 & T1 & T3 \\
\hline Linear & $2.92 \pm 0.20$ & $2.95 \pm 0.14$ & $3.05 \pm 0.197$ \\
Quadrilateral & $4.12 \pm 0.15$ & $4.13 \pm 0.14$ & $4.25 \pm 0.15$ \\
Independent- samples & $<0.001$ & $<0.001$ & $<0.001$ \\
t- test & & & \\
(p value) & & & \\
\hline
\end{tabular}

Statistically significant $p<0.05$

T1: six month after the placement of the attachment
T0: immediately after placement of the attachment

T2: twelve month after the placement of the attachment 


\section{DISCUSSION}

There is limited data dealing with management of mandibular single denture and the use of implants in the management of these cases. Most of studies dealing with implant distribution are in vitro studies, which do not resemble the oral conditions.

Dantas et al. ${ }^{(28)}$ concluded that mandibular overdentures with 4 implants showed better results with respect to survival and success rates, especially those with a bar connection. Further studies comparing these two treatment types are necessary to improve the scientific evidence in this area. With this in mind, they recommended long-term, randomized and appropriately designed clinical studies.

Focusing on soft lining material, we are developing a retention system for overdentures using a soft liner as a female connector. The physical properties of the soft lining materials decrease the burden on abutments due to occlusal forces. Although the retention of the soft lining material is low owing to material's low hardness, the tension force higher than that of rubber O-ring attachment can be achieved by increasing the diameter of the male connector ${ }^{(29)}$.

The results of this study indicated that implant location affects the retention of mandibular single denture retained by four implants, thus rejecting the null hypothesis.

Although retention and its effect on overdenture prosthetic factors are related, studies have not established a consensus regarding what is considered sufficient retention. An in vitro study evaluated several different types of attachments and reported that retention strengths between 5 and $8 \mathrm{~N}$ may be sufficient for implant-retained overdentures during long-term function. ${ }^{(30)}$. A prospective crossover clinical study evaluated patient satisfaction and the correlation to force values, and determined that approximately $10 \mathrm{~N}$ of retention was effective. $^{(31)}$ Patients preferred the attachment that provided greater retention. Based on these 2 established studies, an effective retentive force may be between 8 and $10 \mathrm{~N}$.

The results of this study showed that quadrilateral distribution of implants maximizing retention of mandibular single denture. The results is in agreement with Sherer et al ${ }^{(32)}$ as he concluded from his in vitro study that vertical retention increases with distal implant location up to the second premolar. In the vertical pull tests, the incisor region showed the lowest mean retentive values, which steadily increased as the implant position was moved distally. The highest values were in the second premolar region, and the values dropped when the implants moved into the molar location.. The type of attachment affects the influence of vertically applied forces. ERA and O-Ring attachments showed similar trends to each other. In these attachment types, the highest level of force was required to dislodge the implants located at the first and second premolar locations, and the lowest at the incisor location.

The probing depth in this study was less than three $\mathrm{mm}$. in both groups along periods of study. Mombelli claimed that successful implants generally allow a prop penetration of $3 \mathrm{~mm}$. The author added that, if there are pockets deeper than $3 \mathrm{~mm}$.,an inflammatory process may take place at the bottom of the defect. ${ }^{(33)}$

After one year of this study, there was a statistically significant increased plaque index around implants in both groups. This may be attributed to the hygienic quality of the soft liner which may be related to incorporation of natural floara which is responsible for plaque accumulation.

Significant improvement of bleeding index is in commitment with the healing process and osseointegration occurred in the second and third evaluation intervals. 
Dislodging forces generally increased as implants were spaced further apart on the test model. The results of this study were similar to those found in previous studies in regard to interimplant distance. ${ }^{(34-35)}$ The effect of interimplant spacing was especially evident with the ball-type attachments compared with other attachments.

\section{CONCLUSION}

1- Both linear and quadrilateral distribution showed preservation of implants regarding the periimplant outcome over the period of study.

2- When maximizing retention is needed, quadrilateral distribution is the treatment modality of choice for mandibular single denture.

\section{RECOMMENDATIONS:}

Further prospective studies are needed to evaluate the effect of implants radiographically; also it is important to study the effect of various attachments in various distributions of implants.

\section{REFERENCES:}

1. Anderson, R. Storer. Immediate and Replacements Dentures, Blackwell Scientific Publications, Oxford, $1966 ; 4$

2. Economou PN. Single complete dentures Stomatolgia. 1990; 47;3:181-91.

3. Sheldon Winkler,George E.Monasky; The edentulous mandible opposing natural teeth: Treatment considerations utilizing implant overdentures(Implant Dent 1993;2:44-7

4. BurnsD.R., 2004. The mandibular complete overdenture. Dent.Clin.N.Am48, 603-662

5. Jemt T. Implant treatment in elderly patients. Int $\mathbf{J}$ Prosthodont 1993;6:456-61

6. Naert 3. I, Gizani S, Vuylsteke M, Van Steenberghe D. A 5-year prospective randomized clinical trial on the influence of splinted and unsplinted oral implants retaining a mandibular overdenture: prosthetic aspects and patient satisfaction. J Oral Rehabil 1999; 26:195-202.
7. Sadowsky S. Mandibular implant-retained overdentures: a literature review. J Prosthet 4. Dent 2001; 86:468-73.

8. Wright P5. S, Glantz PO, Randow K, Watson RM. The effects of fixed and removable implant-stabilised prostheses on posterior mandibular residual ridge resorption. Clin Oral Implants Res 2002; 13:169-74.

9. Walton J6. N, MacEntee MI, Glick N. One-year prosthetic outcomes with implant overdentures: a randomized clinical trial. Int J Oral Maxillofac Implants 2002;17:391-8.

10. Visser 7. A, Meijer HJ, Raghoebar GM, Vissink A. Implant-retained mandibular overdentures versus conventional overdentures: 10 years of case and aftercare. Int J Prosthodont 2006; 19:271-8.

11. T ruhlar R8. S, Casino AJ, Cancro JJ. Treatment planning in the elderly implant patient. Dental Clin North Am 1997; 41:847-61.

12. Parel S9. M, Balshi TJ, Sullivan DY. Modifications of existing prosthesis with osseointegrated implants. J Prosthet Dent 1986;56:1

13. Tolga Topkaya, Murat Yavuz Solmaz; The effect of number and position of implants on the stress behavior of mandibular implant retained overdenture: A threedimensional finite element analysis, 2015 Jul 16; 48(10):2102-9. doi: 10.1016/j.jbiomech.2015.03.006. E pub 2015 Mar 20.

14. Swasty D, Lee JS, Huang JC, Maki K, Gansky SA, Hatcher D, et al. Anthropometric analysis of the human mandibular cortical bone as assessed by cone-beam computed tomography. J Oral Maxillofac Surg 2009;67: 491-500.

15. Katranji A, Misch K, Wang HL. Cortical bone thickness in dentate and edentulous human cadavers. J Periodontol 2007; 78:874-8.

16. Neukam FW, Hausamen JE, Schliephake H. Surgical aspects of implant installation. In: Naert I, van Steenberghe D, Worthington P. Osseointegration in oral rehabilitation London: Quintessence; 1993.p. 87-104.

17. Misch CE, Crawford EA. Predictable mandibular nerve location: a clinical zone of safety. Int J Oral Implantol 1990;7:37-40.

18. Apostolakis D, Brown JE. The anterior loop of the inferior alveolar nerve: prevalence, measurement of its length and a recommendation for interforaminal implant installation based on cone beam CT imaging. Clin Oral Impl Res 2012;23:1022-30. 
19. Belser UC, Mericske-Stern R, Bernard JP, Taylor TD. Prosthetic management of the partially dentate patient with fixed implant restorations. Clin Oral Implants Res 2000;11(suppl 1):126-45.

20. Avant WE. Indirect retention in partial denture design. J Prosthet Dent 1966;16: 1103-10.

21. Lekholm U, Zarb GA. Patient selection and preparation. In: Branemark P-I, Zarb GA, Albrektsson T (eds). Tissue integrated prostheses: Osseointegration in clinical dentistry. Chicago: Quintessence 1985: 199-210

22. Cawood JI, Howell RA.: A classification of the edentulous jaws. Int J Oral Maxillofac Surg. 1988;17: 232-6.

23. David R Burns, DMD, John W. Unger, DDS,, James P. Coffey, DDS, Thomas C. Waldrop, DDS, and Ronal K.Elswick, Jr, PhD: Randomaized, prospective,clinical evaluation of Prosthodontic modalities for mandibular implant overdenture treatment. J Prosthet dent 2011; 106:12-22.

24. Mombelli A, Lang NP.: The diagnosis and treatment of peri- implantitis. Periodontol 2000 1998; 17:63-76.

25. Loe H, Silness J.: Periodontal Disease in Pregnancy. I. Prevalence and Severity. Acta Odontol Scand 1963;21:533551

26. Meredith N.: Assessment of implant stability as a prognostic determinant. Int $\mathrm{J}$ Prosthodont 1998; $11: 491-501$.

27. Olive J, Aparicio C.: Periotest method as a measure of osseointegrated oral implant stability. Int J Oral Maxillofac Implants 1990;5:390-400.

28. Isabelle de Sousa Dantas Mariana Barbosa Câmara de Souza Maria Helena de Siqueira Torres M orais Adriana da Fonte Porto Carreiro Gustavo Augusto Seabra Barbosa: Success and survival rates of mandibular overdentures supported by two or four implants: a systematic review Braz Oral Res., (So Paulo) 2014;28(1):1-7

29. Besimo CE, Guarneri A. In vitro retention force changes of prefabricated attachments for overdentures. J Oral Rehabil 2003;30: 671-82

30. Koike T, Ueda T, Noda S,Ogami K,patil GP, Sakurai K : development of new attachment system with soft lining material for implant retained overdenture 2013 IJOPRD $3(1): 21-24$

31. Burns DR, Unger JW, Elswick RK Jr, Beck DA. Prospective clinical evaluation of mandibular implant overdentures: Part Ie-retention, stability, and tissue response. J Prosthet Dent 1995;73:354-63.

32. Michael D. Scherer, DMD, MS, Edwin A. McGlumphy, DDS, MS, Robert R. Seghi, DDS, MS, and Wayne V. Campagni, DMD: Comparison of retention and stability of two implant-retained overdentures based on implant location. J Prosthet. Dent.2014 In press.

33. Mombelli a: Microbiology and antimicrobial therapy of peri-implantitis.Periodontol 2000; 2002, 28:177-89

34. Doukas D, Michelinakis G, Smith PW, Barclay CW. The influence of interimplant distance and attachment type on the retention characteristics of mandibular overdentures on 2 implants: 6-month fatigue retention values. Int J Prosthodont 2008;21: 152-4.

35. Michelinakis G, Barclay CW, Smith PW. The influence of interimplant distance and ttachment type on the retention characteristics of mandibular overdentures on 2 implants: initial retention values. Int J Prosthodont 2006;19:507-12 